\title{
Policy Developments in the USA to Address Platform Information Disorders"
}

\author{
Sarah Hartmann
}

Abstract: This chapter focuses on three factors contributing to the larger problem of information disorders in online platform environments - lack of reliable sources, lack of platform accountability, and lack of competition. By addressing these root causes, legislators can try to reshape the current communication environment in order to make it less vulnerable to information disorders. This chapter highlights current policy proposals and discussions on promoting trustworthy local news, incentivizing platforms to decrease the circulation of harmful speech through reform of Section 230, and increasing competition by mandating data portability and interoperability.

Keywords: Platform Regulation; Disinformation; Section 230 Reform; Intermediary Liability; Local News Subsidies; Data Portability; Interoperability

\section{Chapter 1. Introduction and Overview}

Online platforms are intrinsically linked to information disorders as a petri dish that allows extreme content, conspiracy theories and false information to multiply. ${ }^{1}$ The term "information disorder" refers to content with different levels and combinations of falseness and intent to harm. ${ }^{2}$

* The chapter is based on Prof. Ellen P. Goodman's presentation during the workshop "Platform and Media Regulation - New Trends in Western Democracies" in February 2021. The author would like to thank Prof. Goodman for her helpful and valuable advice and comments.

1 Hunt Allcott and Matthew Gentzkow, "Social media and fake news in the 2016 election”, Stanford University, Journal of Economic Perspectives 31 no. 2 (2017): 221.

2 Unknowingly incorrect representations (mis-information), intentionally manipulating or fabricated content (dis-information) and factual information and speech meant to attack or cause harm, such as hate speech or publication of private in- 
Information disorders include many buzzword phenomena such as "fake news" and "hate speech", but are not limited to these vague terms.

A couple of decades ago, conspiracy theorists did not have the means to reach large audiences, let alone specifically target those they deemed like-minded or receptive to their message. Access to multipliers, such as broadcasting and print media, was controlled by professional journalistic institutions that acted as a filter for extremist or factually false content to protect themselves from liability. At the dawn of the internet age, individual messages could be published through private websites to a potentially unlimited audience. In practice, most private websites remained the online equivalent of soapbox speeches and never attracted wide public attention. Only the emergence of social media platforms introduced the element of amplification to an instant and expanding audience. Unlike legacy media outlets, platforms in their function as intermediaries do not filter content according to journalistic standards ${ }^{3}$ and apply little to no upfront restriction, protected from liability for third party content as "neutral" intermediaries. ${ }^{4}$ Meanwhile, platforms have drained advertising revenues of other media providers, ${ }^{5}$ especially on the local level, ${ }^{6}$ and effectively immunized themselves against potential competitors by holding their user's data hostage.

formation (mal-information), see Claire Wardle and Hossein Derakhshan, Information Disorder: Toward and interdisciplinary framework for research and policy making, (Council of Europe report DGI(2017)09, 2017), 21, https://rm.coe.int/information -disorder-report-version-august-2018/16808c9c77.

3 Ellen P. Goodman, "Digital Information Fidelity and Friction", Knight First Amendment Institute at Columbia University, February 26, 2020, https://knightcol umbia.org/content/digital-fidelity-and-friction.

4 Guy Rolnick et al., Protecting Journalism in the Age of Digital Platforms (Stigler Center for the Study of the Economy and the State, University of Chicago Booth School of Business, July 1, 2019), 190, http://www.columbia.edu/ ap3116/papers/ MediaReportFinal.pdf.

5 Jerrold Nadler, and David N. Cicilline, Investigation of Competition in Digital Markets - majority staff report and recommendations, (Subcommitee on antitrust, commercial and administrative law of the committee on the judiciary, 2020), $57 \mathrm{f}$., https://judiciary.house.gov/uploadedfiles/competition_in_digital_markets.pdf?utm _campaign $=4493-519$.

6 Penelope Muse Abernathy, News Deserts and Ghost Newspapers - Will Local News Survive? (The Center for Innovation and Sustainability in Local media, Hussmann School of Journalism and Media, University of North Carolina at Chapel Hill, 2020), 8, https://www.usnewsdeserts.com/wp-content/uploads/2020/06/2020_News _Deserts_and_Ghost_Newspapers.pdf. 
The effects of this media environment and the consequences of information disorders became especially evident in the United States in 2020 and 2021: from widespread misinformation about COVID-19, such as the alleged inefficacy of wearing face masks, ${ }^{7}$ to allegations of election fraud culminating in the unprecedented capitol riots of January $6^{\text {th }} 2021 .^{8}$ Discussions on the fallout inevitably zeroed in on the role of online platforms ${ }^{9}$ and future preventive measures, with the US Congress holding a hearing ${ }^{10}$ on the role of social media platforms in promoting misinformation and extremist content in late March 2021.

Across-the-board consensus maintains the need for measures against information disorders. This consensus is deceptive, however, as little common ground exists on the issues to be addressed or suitable countermeasures. Therefore, current policy proposals cover several fields and present a wide array of approaches. The following overview focuses on three factors contributing to the larger problem of information disorders -lack of reliable sources, lack of platform accountability, and lack of competition. This overview is not meant to be exhaustive, but instead aims to show the diversity of proposals and highlight the most promising or most prolific current policy approaches. Where appropriate, proposals are put into context with

7 See Richard A. Stein et al., "Conspiracy theories in the era of COVID-19: A tale of two pandemics", The International Journal of Clinical Practice 75 no. 2 (2021), 1, https://www.ncbi.nlm.nih.gov/pmc/articles/PMC7995222/pdf/IJCP-75-e13778.pdf

8 See Timothy W. Luke, "Democracy under threat after 2020 national elections in the USA: 'stop the steal' or 'give more to the grifter-in-chief?", Educational Philosophy and Theory (2021), https:/www.tandfonline.com/doi/pdf/10.1080/0013 1857.2021.1889327?needAccess=true.

9 See Facebook's internal Report "Stop the Steal and Patriot Party: the Growth and Mitigation of an Adversarial Harmful Movement, available through buzzfeednews, April 26, 2021, https://www.buzzfeednews.com/article/ryanmac/full-facebook-sto p-the-steal-internal-report?origin=tuh.

10 See H.R. Committee on Energy and Commerce, Memorandum on joint hearing "Disinformation Nation: Social Media's Role in Promoting Extremism and Disinformation”, March 22, 2021, https://docs.house.gov/meetings/IF/IF16/20210325/1 11407/HHRG-117-IF16-20210325-SD002.pdf 
recent EU initiatives such as the Digital Services Act ${ }^{11}$ and Digital Markets Act. ${ }^{12}$

\section{Chapter 2. Lack of Reliable Sources - Measures against the Decline of Local News}

One factor contributing to the spread of mis- and disinformation is a lack of trusted reporting and distrust in available reporting. ${ }^{13}$ Users are less likely to believe and perpetuate falsehoods if these are presented alongside reliable news on the same topics. An abundance of quality journalistic content in users' timelines might not directly counteract intentional communication of factually incorrect or misleading content, but it would immunize many of its recipients, enabling them to identify information as false. ${ }^{14}$ In essence, enough "good" speech could go a long way towards countering "bad" speech. ${ }^{15}$

Unfortunately, traditional news outlets as a source of "good" speech have for years been suffering from declining revenues and competition with online media. The economic crisis of 2009 and, more recently, the effects $^{16}$ of the COVID-19 pandemic have in particular taken their toll

11 European Commission, "Proposal for a REGULATION OF THE EUROPEAN PARLIAMENT AND OF THE COUNCIL on a Single Market For Digital Services (Digital Services Act) and amending Directive 2000/31/EC”, $\operatorname{COM}(2020) 825$ final, December 15, 2020.

12 European Commission, "Proposal for a REGULATION OF THE EUROPEAN PARLIAMENT AND OF THE COUNCIL on contestable and fair markets in the digital sector (Digital Markets Act)", COM/2020/842 final, December 15, 2020.

13 Rasmus Kleis Nielsen and Lucas Grave, 'News you don't believe': Audience perspectives on fake news (Oxford: Reuters Institute for the Study of Journalism, 2017), 7, https://ora.ox.ac.uk/objects/uuid:6eff4d14-bc72-404d-b78a-4c2573459ab8/downloa d_file?file_format=pdf\&safe_filename=Nielsen $\% 2 \mathrm{~B}-\% 2 \mathrm{BAudience} \% 2 \mathrm{Bperspective}$ s\%2Bon\%2Bfake\%2Bnews.pdf\&type_of_work=Report.

14 Nielsen and Grave, News you don't believe, 5.

15 Marko Milanovic, "Viral Misinformation and the Freedom of Expression: Part I", EJIL:Talk!, Blog of the European Journal of International Law, April 13, 2020, https:// www.ejiltalk.org/viral-misinformation-and-the-freedom-of-expression-part-i/.

16 Anya Schiffrin, Hannah Clifford, and Kylie Tumiatti, Saving Journalism: A Vision for the Post-Covid World (Konrad Adenauer Stiftung, January 2021), $3 \mathrm{f}$. , https://ww w.kas.de/documents/283221/283270/KAS_Saving+Journalism.pdf/8ee31596-716630b4-551f-c442686f91ae?version $=1.4 \& \mathrm{t}=1611338643015$. 
on local newspapers and local broadcasters, the main and most trusted ${ }^{17}$ source of news throughout the country. The system of decentralized and small private news providers was often unable to offer resistance to volatile market conditions. The resulting "news desert" 18 areas without access to local news providers are more vulnerable to unchecked information or misrepresentations that fill the void left behind. ${ }^{19}$

A recent report ${ }^{20}$ by Senator Maria Cantwell identified the market behaviour of dominant online platforms as one of two major reasons for the struggling local news sector. Besides the general loss of ad business to online media, ${ }^{21}$ news outlets suffer from "hijacking" of their content by news aggregators, especially by Google and Facebook, with little to no compensation. ${ }^{22}$ Her findings are in line with the conclusions of a House investigation of competition in digital markets, ${ }^{23}$ which also pointed to the dependency of news outlets on large platforms to disseminate their content. ${ }^{24}$ On the one hand, news aggregation services and platforms are important points of entry to direct users to news sites and generate traffic. $^{25}$ On the other hand, news sites often compete with their own content excerpts and headlines presented by aggregators, rendering a visit to the source webpage unnecessary. ${ }^{26}$ Overall, news content providers lack the bargaining power to determine the conditions of access to their content on platforms. ${ }^{27}$ Changes in the platforms' recommender algorithms, such as Facebook's adjustment to its News Feed in 2018, have had major (negative) financial impacts on news sites and remain completely beyond their control. ${ }^{28}$ Platforms may even place one-sided restrictions on content providers' ability to monetize content on their own sites through ad placement or paywalls, as was recently the case with Google's Accelerated

17 Maria Cantwell, Local Journalism - America's Most Trusted News Sources Threatened (U.S. Senate Committee on Commerce, Science, and Transportation, October 2020), 7 f., https://www.cantwell.senate.gov/imo/media/doc/Local\%20Journalism \%20Report\%2010.26.20_430pm.pdf.

18 Abernathy, News Deserts and Ghost Newspapers, 8.

19 Nadler and Cicilline, Investigation of Competition in Digital Markets, 62.

20 Cantwell, Local Journalism.

21 Cantwell, Local Journalism, $14 \mathrm{f}$.

22 Cantwell, Local Journalism, $28 \mathrm{f}$.

23 Nadler and Cicilline, Investigation of Competition in Digital Markets.

24 Nadler and Cicilline, Investigation of Competition in Digital Markets, 63.

25 Nadler and Cicilline, Investigation of Competition in Digital Markets, 63.

26 Nadler and Cicilline, Investigation of Competition in Digital Markets, 59.

27 Nadler and Cicilline, Investigation of Competition in Digital Markets, 64

28 Nadler and Cicilline, Investigation of Competition in Digital Markets, 63. 
Mobile Pages feature for news. ${ }^{29}$ The program requires news web pages to be hosted on Google's infrastructure with a limited number of ads to allow for faster loading times and features no flexibility for paywalls. ${ }^{30}$

Both the recommendations of the House Investigation and the findings in Senator Cantwell's report suggest an antitrust approach, targeting certain platform business practices as abusive. ${ }^{31}$ Senator Cantwell especially points out the need to address retaliatory practices, like hiding or removing local news content. ${ }^{32}$ In order to improve the disparity between the bargaining power of local news providers and platforms, both reports suggest introducing a (temporary) safe harbour for news publishers and broadcasters to collectively bargain with news aggregators. ${ }^{33}$ The House Investigation references ${ }^{34}$ a draft bill ${ }^{35}$ by Representative Cicilline, who also co-authored the Investigation, which sought to establish a limitation of liability under antitrust law for news content creators. The exemption would apply to negotiations among news content creators to collectively withhold content from online content distributors or collectively negotiate the terms for content distribution, given that the negotiations are non-discriminatory to other news providers and the agreed terms would be available to all news content creators. ${ }^{36}$

The Local Journalism Sustainability Act, ${ }^{37}$ proposed in July 2020 by Representative Kirkpatrick, chooses a different approach, not relying on antitrust law but rather creating tax incentives in order to support local media. According to the draft bill, individuals are allowed tax credits of up to 250 USD for subscriptions to local newspapers ${ }^{38}$ and small businesses ${ }^{39}$ are granted tax credits up to 5.000 USD for advertising in local newspa-

29 Cantwell, Local Journalism, $31 \mathrm{f}$.

30 Nadler and Cicilline, Investigation of Competition in Digital Markets, 65.

31 Cantwell, Local Journalism, 56; Nadler and Cicilline, Investigation of Competition in Digital Markets, $389 \mathrm{ff}$.

32 Cantwell, Local Journalism, 56.

33 Cantwell, Local Journalism, 55; Nadler and Cicilline, Investigation of Competition in Digital Markets, 388.

34 Nadler and Cicilline, Investigation of Competition in Digital Markets, 389.

35 Journalism Competition and Preservation Act of 2019, H.R. 2054, 116 ${ }^{\text {th }}$ Cong. (2019); see also Abernathy, News Deserts and Ghost Newspapers, $83 \mathrm{f}$.

36 See Sec. 2 (b) Journalism Competition and Preservation Act of 2019, H.R. 2054, $116^{\text {th }}$ Cong. (2019).

37 Local Journalism Sustainability Act, H.R. 7640, 116 ${ }^{\text {th }}$ Cong. (2020).

38 The tax credit covers $80 \%$ of the subscription costs for the first year and $50 \%$ for the following years, see Sec. 2 (c) Local Journalism Sustainability Act, H.R. 7640, $116^{\text {th }}$ Cong. (2020).

39 Businesses with less than 1.000 employees. 
pers, radio or television. ${ }^{40}$ Local newspapers are also given direct tax credit for $50 \%$ of their journalistically qualified employees' salaries. ${ }^{41}$

There appears to be hesitation to provide direct state subsidies to local news providers ${ }^{42}$ outside of minor COVID pension relief. ${ }^{43}$ In 2020, Members of the House of Representatives suggested allocating a portion of the government's ad budget to local media. ${ }^{44}$ Civil society proposals $s^{45}$ have meanwhile established the idea of cross-financing journalism through taxes on platform ad or other revenue. ${ }^{46}$ On the state level, Maryland has already introduced a scale tax on revenue from digital ads displayed to citizens of Maryland. ${ }^{47}$ While the tax is not tied to promotion of local journalism and has a strong likelihood of being struck down, it could still serve as a case study for other states in their efforts to fund local news. New Jersey, on the other hand, does not currently tax digital advertising, but has provided funds for the "Civic Information Consortium", ${ }^{48}$ which will distribute grants to projects reviving local media. ${ }^{49}$

40 Sec. 2, 4 Local Journalism Sustainability Act, H.R. 7640, 116 ${ }^{\text {th }}$ Cong. (2020).

41 Up to 12.500 USD per quarter and $30 \%$ from the fifth quarter, see Sec. 3 (b) (1), (c) Local Journalism Sustainability Act, H.E. 7640, $116^{\text {th }}$ Cong. (2020).

42 Schiffrin, Clifford, and Tumiatti, Saving Journalism, 12.

43 Craig Forman, "Covid Relief Bill Throws Lifeline to Transform Local news", NiemanReports, March 10, 2021, https://niemanreports.org/articles/covid-relief-b ill-throws-lifeline-to-transform-local-news/; see also Abernathy, News Deserts and Ghost Newspapers, 80.

44 See the statement of Debbie Dingell et al. of April 20, 2021, https://debbieding ell.house.gov/uploadedfiles/200420supportlocalbroadcasters.pdf; a very similar proposal was brought forward in Rep. Ryan's Protect Local Media Act, H.R. 6913, $116^{\text {th }}$ Cong. (2020).

45 See Schiffrin, Clifford, and Tumiatti, Saving Journalism, 24 f.; see also Guy Rolnick et al., Protecting Journalism, $34 \mathrm{ff}$. with a 'Media-Voucher' proposal; David Ardia et al., "Addressing the decline of local news, rise of platforms, and spread of misand disinformation online - A summary of current research and policy proposals" (Center for Information, Technology, and Public Life, December 2020), https://ci tap.unc.edu/local-news-platforms-mis-disinformation/.

46 Guy Rolnick et al., Protecting Journalism, 54.

47 David McCabe, “Maryland Approves Country's First Tax on Big Tech's Ad Revenue", The New York Times, February 12, 2021, https://www.nytimes.com/2021/02 /12/technology/maryland-digital-ads-tax.html.

48 Sarah Stonbely, Matthew S. Weber, and Christopher Satullo, "Innovation in Public Funding for Local Journalism: A Case Study of New Jersey's 2018 Civic Information Bill”, Digital Journalism 8, no. 6 (2020): 740-757.

49 See Civic Information Consortium, “About the Consortium”, accessed April 27, 2021. https://njcivicinfo.org/about/. 
Chapter 3. Lack of Platform Accountability - Draft Laws to Shrink Section 230 Immunity

A large share of the US debate on online platform regulation revolves around immunity of platforms from liability and lack of effort on their part to intervene against the spread of harmful or illegal content within their own networks. Section 230 (c) in its current form prevents platforms as "providers of interactive computer services" from being treated as the publisher or speaker of information by another information content provider. Furthermore, the Good Samaritan clause in Section 230 (c) (2) excludes civil liability for removal or restriction of content in "good faith". Introduced in the mid-1990s to promote competition with the telecommunications network ${ }^{50}$ and allow new and innovative internet services to establish themselves under protection from liability for third-party content, ${ }^{51}$ the immunity provision has lately been cited as part of the problem in dealing with platforms. Critics from opposing ends of the political spectrum focus on different aspects, for example alleging left-leaning bias in content moderation ${ }^{52}$ and "censorship" by platforms of political opinions, ${ }^{53}$ or suggesting a systemic failure to sufficiently protect vulnerable groups and prevent crime. ${ }^{54}$

Over the last two years, a number of bills to reform platform immunity have been presented, but none have been passed so far. Just since January 2021, seven different draft bills have been introduced or re-introduced

50 Karen Kornbluh and Ellen P. Goodman, "Bringing Truth to the Internet", Democracy Journal no. 53 (2019), https://democracyjournal.org/magazine/53/bringing-tru th-to-the-internet/.

51 Paul M. Barret, Regulating Social Media: the Fight over Section 230 - and Beyond (New York University Stern Center for Business and Human Rights, September 2020), 4, https://static1.squarespace.com/static/5b6df958f8370af3217d4178/t/5f58d f637cbf80185f372776/1599659876276/NYU+Section+230_FINAL+ONLINE+UPD ATED_Sept+8.pdf.

52 See draft bill by Sen. Hawley, Ending Support for Internet Censorship Act, S. 1914, $116^{\text {th }}$ Cong. (2019).

53 See proposal for the CASE-IT Act, introduced by Reps. Steube and Gregory excluding section 230 immunity for providers "stifling free expression", Curbing Abuse and Saving Expression In Technology Act, H.R. 285, 117 ${ }^{\text {th }}$ Cong. (2021); see also a bill recently passed in Florida, fining social media platforms for "deplatforming” (blocking) political candidates, S.B. 7072, 2021 Session (Fla. 2021).

54 See e.g. the Safeguarding Against Fraud, Exploitation, Threats, Extremism, and Consumer Harms Act, S. 299, $117^{\text {th }}$ Cong. (2021). 
from the previous congressional session. ${ }^{55}$ The proposals can be broadly categorized by the kind of content or involvement of the platform they wish to exclude from immunity in the future.

\section{Chapter 3.a. Limiting the Scope for Specific Categories of Content}

The most straightforward and least controversial approach to reforming Section 230 is exclusion of certain categories of content from immunity. Draft bills along these lines are most likely to reach consensus. They continue the idea of existing limitations ${ }^{56}$ for federal crimes, intellectual property violations and sex-trafficking charges. ${ }^{57}$

According to the SAFE TECH Act ${ }^{58}$ of Senator Mark Warner, Section 230 would no longer be viable as a defence against claims on grounds of civil rights violations, cyberstalking, and harassment. ${ }^{59}$ However, the proposal does not introduce explicit liability; it only removes the immunity granted by Section 230 as a "categorical bar" against legal redress by victims. ${ }^{60}$ A narrower carve-out is included in Senator Lindsey Graham's EARN IT Act ${ }^{61}$ concerning child sexual abuse material.

55 See the legislative tracker by Kiran Jeevanjee et al., "All the Ways Congress Wants to Change Section 230”, Slate, March 23, 2021, https:/slate.com/technology/2021/ 03/section-230-reform-legislative-tracker.html.

56 Eric Goldman, "An Overview of the United States Section 230 Internet Immunity", in Online Intermediary Liability, ed. Giancarlo Frosio (Oxford University Press, 2020), $160 \mathrm{ff}$.

57 See 47 USC $\$ 230$ (e); see also Barret, Regulating Social Media, 5.

58 Safeguarding Against Fraud, Exploitation, Threats, Extremism, and Consumer Harms Act, S. 299, $117^{\text {th }}$ Cong. (2021).

59 See Sec. 2 (2) Safeguarding Against Fraud, Exploitation, Threats, Extremism, and Consumer Harms Act, S. 299, 117 ${ }^{\text {th }}$ Cong. (2021).

60 See Mark Warner, "Warner, Hirono, Klobuchar Announce the SAFE TECH Act to Reform Section 230", Press Release, February 5, 2021, https://www.warner.sena te.gov/public/index.cfm/2021/2/warner-hirono-klobuchar-announce-the-safe-techact-to-reform-section-230; The exception to this rule is the FOSTA bill, in force since 2018, which not only withdrew Section 230 protection for facilitation of prostitution, but also instated a new offence, see 18 USC $\$ 2421 \mathrm{~A}$.

61 Eliminating Abusive and Rampant Neglect of Interactive Technologies Act of 2020, S. 3398, $116^{\text {th }}$ Cong. (2020). 


\section{Chapter 3.b. Amplification, Recommendation or Monetization of Content}

Other initiatives focus on platform interactions with and treatment of third-party content, rather than the content itself. A bill introduced by Representatives Malinowski and Eshoo in October $2020^{62}$ seeks to limit the scope of Section 230 in cases where the platform's algorithm has influenced the display of content to individual users, for example by ranking, recommendation or amplification, and the affected information is directly relevant to the claim. A similar legal argument was presented by plaintiffs in the Force v. Facebook case. ${ }^{63}$ In his partially dissenting opinion, Judge Katzmann concurred that the limitation of liability in Section 230(c) (1) did not extend to Facebook's friend- and content-suggestion algorithms as they constitute original and separate messages from the content itself. ${ }^{64}$ The majority opinion, however, rejected this notion. ${ }^{65}$ The immunity exception proposed by Malinowski and Eshoo is only applicable to civil action claims on grounds of civil rights violations or terrorism. ${ }^{66}$ The bill also defines certain algorithmic actions as "obvious, understandable, and transparent" which do not trigger the immunity exception, such as sorting information chronologically, alphabetically, or by user rating.

The SAFE TECH Act, mentioned above, limits the scope of Section 230 from a different angle. The bill excludes immunity for content that users or providers have been paid to make available. ${ }^{67}$ The provision is meant to apply to advertisements which are placed and disseminated on platforms against payment, but could also be interpreted as including paid cloud services or paid prioritization.

Both proposals draw a dividing line between content that is treated "neutrally" or "passively" and instances where services actively intervene in content dissemination. Only services in the former category would continue to be protected from liability, while Section 230 would no longer apply to the latter category. ${ }^{68}$ This differentiation is similar to the EU's liability

62 Protecting Americans from Dangerous Algorithms Act, H.R. 8636, 116 ${ }^{\text {th }}$ Cong. (2020).

63 Force v. Facebook, Inc., 934 F.3d 53 (2d Cir. 2019).

64 Force v. Facebook, Inc., 934 F.3d 53 (2d Cir. 2019), 82.

65 Force v. Facebook, Inc., 934 F.3d 53 (2d Cir. 2019), 66.

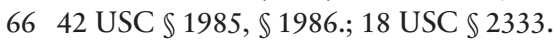

67 Sec. 2 (1) (a) Safeguarding Against Fraud, Exploitation, Threats, Extremism, and Consumer Harms Act, S. 299, 117 ${ }^{\text {th }}$ Cong. (2021).

68 A similar approach was suggested by Rolnick et al., Protecting Journalism, 16. 
privilege for hosting services, ${ }^{69}$ which also relies on determining whether the provider's relationship with third party content is "of a mere technical, automatic or passive nature"..$^{70}$ According to European Court of Justice case-law, online platforms such as eBay start being "actively" involved once they help optimize and promote individual sale offers, for example by placing ads for the offer in search engines. ${ }^{71}$ As a consequence, the hosting privilege does not apply to eBay in this case. However, just as under Section 230, excluding the liability privilege does not lead to automatic liability, which must be provided separately by national or European law. ${ }^{72}$

\section{Chapter 3.c. Additional Obligations as Prerequisites for Immunity}

Finally, different legislative and academic proposals seek to introduce new accompanying obligations for platforms either as prerequisites for Section 230 immunity or as separate duties. The idea of "earned" immunity has been discussed by Citron and Wittes, for example, on the condition of reasonable moderation practices, ${ }^{73}$ and recommended in the Stigler report in the form of a "quid pro quo" for fulfilment of obligations mainly relating to transparency. ${ }^{74}$ In the context of the recent congressional hearing, Mark Zuckerberg of Facebook expressed support for a similar system of conditional immunity, requiring compliance with best practice standards of content moderation and systems to identify and remove harmful content. ${ }^{75}$ On the other hand, this approach has been criticized for conflating

69 Currently Art. 14 Directive 2000/31/EC of the European Parliament and of the Council of 8 June 2000 on certain legal aspects of information society services, in particular electronic commerce, in the Internal Market ('Directive on electronic commerce'), OJ L 178, 17.7.2000, p. 1-16; see also Art. 5 Digital Services Act proposal, $\operatorname{COM}(2020) 825$ final.

70 Rec. 42 Directive on electronic commerce.

71 Case C-324/09, L'Oréal SA v eBay International AG [2011] ECR I-06011, marginal no. 116.

72 See Rec. 17 Digital Services Act proposal, COM(2020) 825 final.

73 Danielle Keats Citron and Benjamin Wittes, “The Problem isn't just Backpage: Revising Section 230 Immunity", Georgetown Law Technology Review (2018): 453.

74 Rolnick et al., Protecting Journalism in the Age of Digital Platforms, 195.

75 Disinformation Nation: Social Media's Role in Promoting Extremism and Disinformation: joint hearing before the United States House of Representatives Committee on Energy and Commerce Subcommittees on Consumer Protection \& Commerce and Communications \& Technology, March 25, 2021, Testimony of Mark Zuckerberg of Facebook, Inc., 7, https://docs.house.gov/meetings/IF/IF16/20210325/111407/HH RG-117-IF16-Wstate-ZuckerbergM-20210325-U1.pdf. 
the question of liability with other policy goals, which should be regulated separately. ${ }^{76}$

A draft bill by Senators Schatz and Thune, the PACT Act, ${ }^{77}$ contains both comprehensive transparency and moderation provisions, such as a duty to explain content moderation practices to users and establish a user complaint mechanism, ${ }^{78}$ as well as a notice-and-takedown system tied to Section 230. According to the proposal, the liability privilege only applies to platforms who have either no knowledge of the content in question or have taken the necessary steps to review and remove or otherwise restrict the content after receiving notice. ${ }^{79}$ This approach most closely resembles the current EU regime of the E-Commerce Directive and the Digital Services Act proposal, where the liability privilege and additional obligations are also regulated separately. Article 14 (1) of the E-Commerce Directive exempts hosting services from liability if they either have no knowledge of illegal activity or information or, upon obtaining such knowledge, restrict the content in question. The Digital Services Act proposal builds upon the principle of hosting privilege, but links it to a notice and action mechanism, mandatory for online platforms. ${ }^{80}$ Qualified notices issued through this mechanism are "considered to give rise to actual knowledge or awareness", thereby obligating the platform to act upon the notice in order to benefit from the hosting privilege..$^{81}$ Other obligations of intermediary services in the Digital Services Act proposal ${ }^{82}$ are not directly linked to liability but subject to enforcement and monetary penalties in case of non-compliance. ${ }^{83}$

76 Mark MacCarthy, "Back to the future for Section 230 reform", Brookings Techtank, March 17, 2021, https://www.brookings.edu/blog/techtank/2021/03/17/back-to-th e-future-for-section-230-reform/

77 Platform Accountability and Consumer Transparency Act, S. 4066, 116 ${ }^{\text {th }}$ Cong. (2020).

78 Sec. 5 (a) and (b) Platform Accountability and Consumer Transparency Act, S. $4066,116^{\text {th }}$ Cong. (2020).

79 Sec. 6 (a) Platform Accountability and Consumer Transparency Act, S. 4066, 116 ${ }^{\text {th }}$ Cong. (2020).

80 Art. 14 Digital Services Act proposal, $\operatorname{COM}(2020) 825$ final.

81 Art. 14 (3) Digital Services Act proposal, COM(2020) 825 final.

82 Art. 10 ff. Digital Services Act proposal, $\operatorname{COM}(2020) 825$ final.

83 See Art. 42 Digital Services Act proposal, COM(2020) 825 final. 


\section{Chapter 4. Lack of Competition - Introducing Portability and Interoperability}

Finally, an important characteristic of the current environment that facilitated the spread of information disorders is the high concentration in the platform market. General antitrust efforts in dealing with online platforms have increased in the USA ${ }^{84}$ and elsewhere. There is considerably less hesitation in turning to antitrust law than to introducing media regulation.

Among the complex causes of platform dominance are so-called lock-in effects; these disincentivise users of one service from switching to alternate providers or using several services in parallel. ${ }^{85}$ This, in turn, creates high entry barriers for competitors and renders users and the platform service as a whole more vulnerable to information disorders within the network. ${ }^{86}$ In order to alleviate the barriers around online platforms that keep users in and competitors out, the introduction of interoperability ${ }^{87}$ and portability ${ }^{88}$ rules has been discussed. ${ }^{89}$ In theory, data portability would empower users to take the information linked to their accounts from one platform to another platform, ${ }^{90}$ the digital equivalent of moving apartments and bringing every piece of furniture along to the new apartment. Interoperability on the other hand would enable different platforms' systems to connect and communicate with one another through mutually established protocols. ${ }^{91}$ Much as clients of different mobile providers are able to exchange calls and messages, ${ }^{92}$ YouTube users might be able to send private messages to Instagram users and vice versa. In the context of information disorders, interoperability and data portability could potentially foster competition between different platforms' algorithms.

84 See Nadler and Cicilline, Investigation of Competition in Digital Markets.

85 Nadler and Cicilline, Investigation of Competition in Digital Markets, 384.

86 Judit Bayer et al., Disinformation and propaganda - impact on the functioning of the rule of law in the EU and its Member States (Study for the European Parliament, 2019), 136, https://www.europarl.europa.eu/RegData/etudes/STUD/2019/608864/I POL_STU(2019)608864_EN.pdf.

87 Wolfgang Kerber and Heike Schweitzer, "Interoperability in the Digital Economy", JIPITEC 8 no. 1 (2017): 39, https://www.jipitec.eu/issues/jipitec-8-1-2017/453 1.

88 Ruth Janal, "Data Portability - A Tale of Two Concepts”, JIPITEC 8 no. 1 (2017): 59, https://www.jipitec.eu/issues/jipitec-8-1-2017/4532.

89 Nadler and Cicilline, Investigation of Competition in Digital Markets, $385 \mathrm{ff}$.

90 Janal, "Data Portability", 60; Nadler and Cicilline, Investigation of Competition in Digital Markets, 386.

91 Kerber and Schweitzer, "Interoperability in the Digital Economy", 40; Nadler and Cicilline, Investigation of Competition in Digital Markets, 385.

92 Rolnick et al., Protecting Journalism in the Age of Digital Platforms, 16. 
A draft bill from 2019 by Senators Warner and Hawley, the ACCESS Act, ${ }^{93}$ proposed the introduction of a portability duty for platforms with more than 100,000,000 monthly active users in the USA. Platforms would be obligated to implement a system for the transfer of user data in a structured, commonly used and machine-readable format to other communication providers at the discretion of the user. ${ }^{94}$ The bill also included an interoperability duty for the same platforms, requiring accessible interfaces to allow communications with users of competing providers. ${ }^{95}$ Platform providers that operate several platforms or other products and services that are interoperable (such as Facebook and Instagram) are additionally required to provide a functionally equivalent version of their interface to competitors. ${ }^{96}$ Finally, the interoperability requirement is also extended to custodial third party services that users may employ to manage their account settings, content, and online interactions. ${ }^{97}$ Custodial services are bound by a duty of care and must be granted access to all functions available to the user on the same terms as the user. In theory, a third party service like this could be used across several platforms as a one-stop-shop for settings and communications, aggregating messages and other content for the user.

The ACCESS Act's interoperability requirements exceed the current EU framework..$^{98}$ The recent EU Commission proposal for a Digital Markets Act only includes interoperability requirements for gatekeepers' operating systems with third-party software and ancillary services, which do not apply to core platform services. ${ }^{99}$ While the ACCESS ACT would obligate a platform like Facebook to enable its users to communicate with users

93 Augmenting Compatibility and Competition by Enabling Service Switching Act of 2019, S. 2658, $116^{\text {th }}$ Cong. (2019).

94 Sec. 3 Augmenting Compatibility and Competition by Enabling Service Switching Act of 2019, S. 2658, $116^{\text {th }}$ Cong. (2019).

95 Sec. 4 Augmenting Compatibility and Competition by Enabling Service Switching Act of 2019, S. 2658, $116^{\text {th }}$ Cong. (2019).

96 Sec. 4 (3) Augmenting Compatibility and Competition by Enabling Service Switching Act of 2019, S. 2658, $116^{\text {th }}$ Cong. (2019).

97 Sec. 5 Augmenting Compatibility and Competition by Enabling Service Switching Act of 2019, S. 2658, $116^{\text {th }}$ Cong. (2019).

98 Rec. 68 General Data Protection Regulation only “encourages” development of interoperable formats instead of obliging data controllers, Regulation (EU) 2016/679 of the European Parliament and of the Council of 27 April 2016 on the protection of natural persons with regard to the processing of personal data and on the free movement of such data, and repealing Directive 95/46/EC (General Data Protection Regulation), OJ L 119, 4.5.2016, 1-88.

99 Art. 6 sec. 1 lit. c, f Digital Markets Act proposal, COM/2020/842 final. 
of other platforms, e.g. share content with them, the Digital Markets Act proposal only prevents operating systems or device manufacturers (such as Google Android) from restricting installation of third-party applications. ${ }^{100}$

In terms of portability, the wording of Sec. 3 in the ACCESS Act proposal is reminiscent of the Right to Data Portability in Article 20 of the EU General Data Protection Regulation (GDPR). Both concepts share one vital restraint, though: While they establish an obligation to transfer user data to the individual user or another provider, there is no equivalent obligation for other providers to enable reception of such data. As a competition tool, data portability requires a suitable destination for user data, i.e. a competing online platform with similar features for storing and displaying content that the user wishes to import. This will not be technically possible in many cases. Like an oversized couch that just will not fit into a new apartment, Facebook account data, including photos and other media, could hardly be imported to a platform such as Twitter. Nevertheless, interoperability and portability can be important building blocks in broader competition policy. ${ }^{101}$

\section{Chapter 5. Conclusion}

What does the future hold for regulation of information disorders on online platforms? Considering the fragmented policy proposals highlighted above, we cannot be sure. This is partially due to the diffuse nature of information disorders that do not lend themselves to traditional regulation. Rather, legislators can only try to reshape certain aspects of online communication in order to indirectly counteract information disorders.

The most prominent topic of recent policy debate in connection with platforms has been the reform of Section 230 immunity. To a certain extent, Section 230 has become a symbol of many things regarded as "wrong" with the current framework for online platforms. It is important to keep in mind, however, that Section 230 is not a blanket provision for content moderation, but a rule specifically addressing provider's liability

100 Rec. 52 Digital Markets Act proposal, COM/2020/842 final.

101 Paul de Hert et al, "The right to data portability in the GDPR: Towards user-centric interoperability of digital services”, Computer Law \& Security Review 34 no. 2 (2018): 194, https://www.sciencedirect.com/science/article/pii/S02673649173033 33?via\%3Dihub\#fn0300; Rolnick et al., Protecting Journalism in the Age of Digital Platforms, 16. 
for illegal content. With its free speech protection famously one of the strongest in the world, ${ }^{102}$ only very few categories of illegal content exist in the USA, in contrast to the European legal framework. ${ }^{103}$ Especially pertaining to mostly legal but harmful disinformation, debates on general platform liability tend to generate more smoke than fire. ${ }^{104}$ Among the reform approaches discussed above, only those including additional requirements for immunity as a "quid pro quo" 105 or implementing new regulatory obligations independent of liability ${ }^{106}$ have the potential to go beyond this limited impact. The proposals share a stronger emphasis on systemic features, such as transparency, addressing platform design and not individual content, and are comparable to the approach in the European Digital Services Act proposal. This is preferable, as it avoids turning either the government or platforms into arbiters of acceptable speech. ${ }^{107}$

A positive approach against information disorders would be promotion of trustworthy news over sensationalist or dubious content. Above all, this requires a viable environment for local news providers. Proposed solutions tackling their current decline range from antitrust remedies to tax incentives, but shy away from providing direct government funding. In theory, promotion of local news as public value content on online platforms could also be mandated as a design feature in connection with immunity requirements. ${ }^{108}$

Lastly, antitrust efforts addressing the market dominance of (certain) online platforms have increased in the last years. In order to show a positive effect as a remedy for information disorders, competitors would first have to establish themselves in a very concentrated platform market. Interoperability and portability requirements as proposed by the ACCESS Act could be helpful in counteracting information disorders, although the

102 Kate Jones, Online Disinformation and Political Discourse - Applying a Human Rights Framework, (Chatham House, 2019), 19, https://www.chathamhouse.org/si tes/default/files/2019-11-05-Online-Disinformation-Human-Rights.pdf.

103 Barret, Regulating Social Media, 6.

104 MacCarthy, "Back to the future".

105 See Citron and Wittes, “The Problem isn't just Backpage”, 471; Rolnick et al., Protecting Journalism, 195.

106 See Sec. 5 Platform Accountability and Consumer Transparency Act, S. 4066, $116^{\text {th }}$ Cong. (2020).

107 Kornbluh and Goodman, "Bringing Truth to the Internet".

108 Bernd Holznagel and Sarah Hartmann, "Reforming competition and media law - the German approach” In Regulating Big Tech: Policy Responses to Digital Dominance, eds. Martin Moore and Damian Tambini (Oxford University Press, 2021). 
portability obligation already established in European law has not had a major impact in that regard.

Overall, most policy proposals do not specifically address information disorders, but rather are primarily geared towards other issues, like press subsidies, liability, and economic competition. Progress likely depends on many of the proposed measures interlinking to achieve a policy sum that is greater than its individual parts.

\section{Bibliography}

Abernathy, Penelope. News Deserts and Ghost Newspapers - Will Local News Survive? University of North Carolina at Chapel Hill, Hussmann School of Journalism and Media, The Center for Innovation and Sustainability in Local media, 2020. https://www.usnewsdeserts.com/wp-content/uploads/2020/06/2020_News_Deser ts_and_Ghost_Newspapers.pdf.

Allcott, Hunt and Gentzkow, Matthew. "Social media and fake news in the 2016 election." Stanford University, Journal of Economic Perspectives 31 no. 2 (2017): 211-236. https://web.stanford.edu/ gentzkow/research/fakenews.pdf.

Ardia, David, Ringel, Evan, Smith Ekstrand, Victoria and Fox, Ashley. "Addressing the decline of local news, rise of platforms, and spread of mis- and disinformation online - A summary of current research and policy proposals." University of North Carolina, Center for Information, Technology, and Public Life, December 2020. https://citap.unc.edu/local-news-platforms-mis-disinformation/.

Barret, Paul. Regulating Social Media: the Fight over Section 230 - and Beyond. New York University Stern Center for Business and Human Rights, September 2020. https://static1.squarespace.com/static/5b6df958f8370af3217d4178/t/5f58df637cb f80185f372776/1599659876276/NYU+Section+230_FINAL+ONLINE+UPDATE D_Sept+8.pdf.

Bayer, Judit, Bitiukova, Natalija, Bárd, Petra, Szakács, Judit, Alemanno, Alberto, and Uszkiewicz, Erik. Disinformation and propaganda - impact on the functioning of the rule of law in the EU and its Member States. Study for the European Parliament, 2019. https://www.europarl.europa.eu/RegData/etudes/STUD/2019/ 608864/IPOL_STU(2019)608864_EN.pdf.

Cantwell, Maria. Local Journalism - America's Most Trusted News Sources Threatened. U.S. Senate Committee on Commerce, Science, and Transportation, October 2020. https://www.cantwell.senate.gov/imo/media/doc/Local\%20Journalism\%20 Report\%2010.26.20_430pm.pdf.

Citron, Danielle Keats and Wittes, Benjamin. "The Problem isn't just Backpage: Revising Section 230 Immunity." Georgetown Law Technology Review 2, no. 2 (2018): 453-473. https://papers.ssrn.com/sol3/papers.cfm?abstract_id=3218521.

Forman, Craig. "Covid Relief Bill Throws Lifeline to Transform Local news." NiemanReports, March 10, 2021. https://niemanreports.org/articles/covid-relief-bi ll-throws-lifeline-to-transform-local-news/. 
Goldman, Eric. "An Overview of the United States Section 230 Internet Immunity." In Online Intermediary Liability, edited by Giancarlo Frosio, 155-171. Oxford University Press, 2020.

Goodman, Ellen. "Digital Information Fidelity and Friction." Knight First Amendment Institute at Columbia University, February 26, 2020. https://knightcolumbia. org/content/digital-fidelity-and-friction.

de Hert, Paul, Papakonstantinou, Vagelis, Malgieri, Gianclaudio, Beslay, Laurent, and Sanchez, Ingacio. "The right to data portability in the GDPR: Towards user-centric interoperability of digital services." Computer Law \& Security Review 34 no. 2 (2018): 193-203. https://www.sciencedirect.com/science/article/pii/S026 7364917303333 ?via\%3Dihub\#fn0300.

Holznagel, Bernd and Hartmann, Sarah. „Reforming competition and media law - the German approach." In Regulating Big Tech: Policy Responses to Digital Dominance, edited by Martin Moore and Damian Tambini. Oxford University Press, 2021.

Janal, Ruth. "Data Portability - A Tale of Two Concepts.", Journal of Intellectual Property, Information Technology and E-Commerce Law 8 no. 1 (2017): 59-69. https://www.jipitec.eu/issues/jipitec-8-1-2017/4532.

Jeevanjee, Kiran, Lim, Brian, Ly, Irene, Perault, Matt, Ruddock, Jenna, Schmeling, Tim, Vattikonda, Niharika, and Zhou, Joyce. "All the Ways Congress Wants to Change Section 230", Slate, March 23, 2021. https://slate.com/technology/2021/0 3/section-230-reform-legislative-tracker.html.

Jones, Kate. Online Disinformation and Political Discourse - Applying a Human Rights Framework. Chatham House, 2019. https:/www.chathamhouse.org/sites/default/ files/2019-11-05-Online-Disinformation-Human-Rights.pdf.

Kerber, Wolfgang and Schweitzer, Heike. "Interoperability in the Digital Economy." Journal of Intellectual Property, Information Technology and E-Commerce Law 8 no. 1 (2017): 39-58. https://www.jipitec.eu/issues/jipitec-8-1-2017/4531.

Kornbluh, Karen and Goodman, Ellen. „Bringing Truth to the Internet.“ Democracy Journal no. 53 (2019), https://democracyjournal.org/magazine/53/bringing-tru th-to-the-internet/.

Luke, Timothy. "Democracy under threat after 2020 national elections in the USA: 'stop the steal' or 'give more to the grifter-in-chief?", Educational Philosophy and Theory (2021). https:/www.tandfonline.com/doi/pdf/10.1080/00131857.2021.18 89327?needAccess=true.

MacCarthy, Mark. "Back to the future for Section 230 reform." Brookings Techtank, March 17, 2021. https:/www.brookings.edu/blog/techtank/2021/03/17/back-to-t he-future-for-section-230-reform/.

McCabe, David. "Maryland Approves Country's First Tax on Big Tech's Ad Revenue.”, The New York Times, February 12, 2021. https://www.nytimes.com/2021/ 02/12/technology/maryland-digital-ads-tax.html.

Milanovic, Marko "Viral Misinformation and the Freedom of Expression: Part I.” EJIL:Talk!, Blog of the European Journal of International Law, April 13, 2020. https://www.ejiltalk.org/viral-misinformation-and-the-freedom-of-expression-par $\mathrm{t}-\mathrm{i} /$. 
Nadler, Jerrold and Cicilline, David. Investigation of Competition in Digital Markets majority staff report and recommendations. Subcommitee on antitrust, commercial and administrative law of the committee on the judiciary, 2020. https://judiciary .house.gov/uploadedfiles/competition_in_digital_markets.pdf?utm_campaign=4 493-519.

Nielsen, Rasmus and Grave, Lucas 'News you don't believe': Audience perspectives on fake news. Oxford: Reuters Institute for the Study of Journalism, 2017. https://or a.ox.ac.uk/objects/uuid:6eff4d14-bc72-404d-b78a-4c2573459ab8/download_file?f ile_format=pdf\&safe_filename=Nielsen $\% 2 \mathrm{~B}-\% 2 \mathrm{BAudience} \% 2 \mathrm{Bperspectives} \% 2 \mathrm{~B}$ on $\% 2$ Bfake\%2Bnews.pdf\&type_of_work=Report.

Rolnick, Guy, Cagé, Julia, Gans, Joshua, Goodman, Ellen, Knight, Brian, Prat, Andrea, Schiffrin, Anya, and Raj, Prateek. Protecting Journalism in the Age of Digital Platforms. Stigler Center for the Study of the Economy and the State, University of Chicago Booth School of Business, July 1, 2019. http://www.colum bia.edu/ ap3116/papers/MediaReportFinal.pdf.

Schiffrin, Anya, Clifford, Hannah, and Tumiatti, Kylie. Saving Journalism: A Vision for the Post-Covid World. Konrad Adenauer Stiftung, January 2021. https://www.k as.de/documents/283221/283270/KAS_Saving+Journalism.pdf/8ee31596-7166-30 b4-551f-c442686f91ae?version $=1.4 \& \mathrm{t}=1611338643015$.

Stein, Richard, Ometa, Oana, Shetty, Sarah, Katz, Adi, Popitiu, Mircea, and Brotherton, Robert. "Conspiracy theories in the era of COVID-19: A tale of two pandemics." The International Journal of Clinical Practice 75 no. 2 (2021): 1-5. https:/www.ncbi.nlm.nih.gov/pmc/articles/PMC7995222/pdf/IJCP-75-e13778.p df.

Stonbely, Sarah, Weber, Matthew and Satullo, Christopher. „Innovation in Public Funding for Local Journalism: A Case Study of New Jersey's 2018 Civic Information Bill.”, Digital Journalism 8, no. 6 (2020): 740-757.

Wardle, Claire and Derakhshan, Hossein. Information Disorder: Toward and interdisciplinary framework for research and policy making. Council of Europe report DGI(2017)09, 2017. https://rm.coe.int/information-disorder-report-version-augu st-2018/16808c9c77. 
